\title{
A narrative inquiry into the identity formation of Chinese doctoral students in relation to study abroad
}

Article

Accepted Version

Ye, L. and Edwards, V. (2017) A narrative inquiry into the identity formation of Chinese doctoral students in relation to study abroad. Race, Ethnicity and Education, 20 (6). pp. 865876. ISSN 1470-109X doi:

https://doi.org/10.1080/13613324.2017.1294570 Available at https://centaur.reading.ac.uk/69111/

It is advisable to refer to the publisher's version if you intend to cite from the work. See Guidance on citing.

Published version at: http://www.tandfonline.com/doi/full/10.1080/13613324.2017.1294570

To link to this article DOI: http://dx.doi.org/10.1080/13613324.2017.1294570

Publisher: Taylor \& Francis

All outputs in CentAUR are protected by Intellectual Property Rights law, including copyright law. Copyright and IPR is retained by the creators or other copyright holders. Terms and conditions for use of this material are defined in the End User Agreement.

www.reading.ac.uk/centaur 
Central Archive at the University of Reading

Reading's research outputs online 


\title{
A narrative inquiry into the identity formation of Chinese doctoral students in relation to study abroad
}

\section{Lily Ye and Viv Edwards*}

Institute of Education, University of Reading

*Corresponding author v.k.edwards@reading.ac.uk

\begin{abstract}
The present study explores a topic which has been under-studied to date, namely the identity formation of Chinese PhD students in relation to study abroad.

Underpinned by Giddens' (1991) "reflexive project of the self”, which privileges agency and reflexivity, and using a narrative inquiry approach, it presents four students 'stories' collected through semi-structured interviews and focus group discussions in the form of a trajectory of development from past to future. In building a picture of the ways in which students' self-identity is shaped by and shapes their experience of study abroad, the stories illustrate individual agency, motivation, selfdetermination and reflexivity. In doing so, they challenge the essentialised view of Chinese students as a homogeneous and sometimes problematic group and point to implications for action by the host institutions.
\end{abstract}

\section{Keywords}

Chinese doctoral students; intercultural communication; identity; international education; study abroad

\section{Introduction}

The last two decades have seen enormous growth in the number of students studying outside their home countries. In the UK, for instance, international students now make up $13 \%$ of all students in higher education (HESA, 2007). Of these, the 80,000 Mainland Chinese students ${ }^{1}$ registered in the academic year 2013/14 constituted the largest group (UKCISA, 2015). Their numbers are predicted to grow still further: a British Council report (Böhm, Follari, Hewett et. al., 2004) estimates that by 2020 there could be over 130,000 Chinese students in the UK. While study

\footnotetext{
${ }^{1}$ Although Mainland China and Hongkong share the same cultural roots, they differ in certain social, economic and political aspects. In recognizing these differences, this study only focuses on Mainland Chinese students.
} 
abroad is a topic which is attracting considerable interest among researchers (see e.g. Ye and Edwards, 2015; Wu, 2014; Durkin, 2011; Gu. et. al., 2010; Tian and Lowe, 2009; Ding, 2009; Gills, 2007; Bryam and Feng, 2006; Yoon \& Portman, 2004; Lin \& Yi, 1997), the majority of studies in this area focus on the need for international students to adjust to local conditions or norms. In contrast, we aim to produce more nuanced understandings of the situation by foregrounding Chinese doctoral students' narratives of their experience rather than the perceptions of teachers and administrators in the host institutions.

We will start with a brief discussion of previous research in this area, before discussing the theoretical framework for the present study, justifying the methodology which it employs and presenting the main findings which emerge from an analysis of the student narratives.

\section{Previous studies of Chinese international students}

Research on international students and study abroad is undertaken within a number of theoretical frameworks, including cultural studies (e.g. Abubaker, 2008), acculturation theory (e.g. Rudmin 2003), second language acquisition/English for academic purposes (e.g. Huang, 2010; Vansteenkiste, Zhou, Lens et al., 2005); and social psychology (Spencer-Oatey \& Xiong, 2006), all of which treat international education as a process of "adjustment" to local norms (Margrison, 2014, p.7). In relation to Chinese students, in particular, proficiency in English, autonomous learning and social interaction emerge as recurrent themes in this body of research with relevance for the present study.

The importance of English proficiency has been underlined by the rapid development of English for Academic Purposes (EAP) programmes designed to provide students with the skills required to perform successfully across core subjects areas in university settings. Campbell \& Li (2008), Cortazzi \& Jin (2000), Ryan \& Hellmundt (2005) and Swagler \& Ellis (2003) are among the many researchers who discuss the influence of the limited competence in English and the related issue of unfamiliarity with the cultural norms of the host country on intercultural adjustment. 
A parallel requirement concerns learning styles. $\mathrm{PhD}$ students are expected to develop as autonomous and independent researchers in their specialised fields (Johnson, Lee \& Green, 2000; Phillips, 1994; Ryan \& Zuber-Skerritt, 1999; Wright and Lodwick, 1989). Researchers such as Biggs (1996), Bryce (2003), and Hockey (1994), however, consider that Chinese students are reluctant to take control of their own learning and so experience a difficult transition to the autonomous learning widely held to be essential for successful doctoral study.

A third area of adjustment highlighted in research relates to perceived difficulties experienced in social interaction with non-Chinese speakers (Spencer-Oatey \& Xiong, 2006; Yuan, 2011). Bock (1970), for instance, highlights the plight of international students unfamiliar with new sociocultural norms and rules to guide their actions and to understand others' behaviours.

The picture which emerges from many studies, then, is one of Chinese students as passive and dependent learners who prefer to socialise with their compatriots: the emphasis is thus on what they lack rather than what they bring to the new setting. Various critical voices, however, have been raised in relation to the essentialism which is often a feature in discussions of this group. Goode (2007), for instance, points out that international $\mathrm{PhD}$ students are not a homogenous group, who are "intrinsically 'problematic' by virtue of being 'hard work' to supervise" (p.592). In a similar vein, researchers such as Grimshaw (2007) advocate that Chinese students should not be treated as a culturally and academically homogeneous group while Dervin (2011), in a similar vein, argues for a non-essentialist approach to the study of the acculturation of Chinese students (see also Feng, 2009; Kumaravadivelu, 2003; Holliday, 1999; Stephens, 1997). Edwards and An (2006) lend support for this position. In addition, a small number of studies focus on negative experiences, such as marginalisation, perceived discrimination, prejudice, stereotypes and racism (see, for instance, Brown 2009; Tian and Lowe, 2009; Hseih, 2006). In this paper we, too, aim to move away from the essentialism and 'othering' of much earlier work by addressing the complexities and nuances of the identity formation of Mainland Chinese. 


\section{Theoretical underpinnings}

Giddens' (1991) 'project of the reflexive self' draws on a number of key concepts helpful in the exploration of identity and provides the theoretical framework for this study. In Giddens' view, self-identity cannot be anchored in collective categories such as race, gender, age or social class in a post-traditional world where viewpoints are no longer influenced by custom. Neither fixed nor given, it is best understood in terms of biographies in which, "at each moment, or at least at regular intervals, the individual is asked to conduct a self-interrogation in terms of what is happening" (p.76). As individuals create, maintain and revise the biographical narrative of who they are, they are better able to make sense of their daily life, to achieve ontological security (or order and continuity) and move toward self-actualisation (or the desire to become everything that we are capable of becoming) through life planning.The usefulness of this approach for present purposes lies in the fact that, while transitional moments such as the decision to study abroad can generate uncertainty and anxiety, they also provide opportunities for personal development. The emphasis on individual agency in coherent, yet continuously revised, biographical accounts thus challenges the traditional view of identity as the characteristics either of individuals or all members of a particular social group.

\section{Methodology}

We use a narrative inquiry approach compatible with Giddens' theorisation of identity in which narratives are both the methodology of inquiry and the research data; in the present study, they include participants' biographical details and dialogues between one of the authors $(\mathrm{Ye})$ and other participants through semi-structured interviews and focus group discussions. For Connelly and Clandinin (2006, p.375), narrative inquiry is "the study of experience as story"; it is "first and foremost a way of thinking about experience". As Brockmeier and Carbaugh (2001, p.1) argue, its importance lies in its "expressive embodiment of our experience, as a mode of communication, and as a form for understanding the world and ultimately ourselves". The focus of narrative research, then, is on the individual, and the fact that life can be understood through a recounting and reconstruction of the life story or biographical narrative. 
In order to address the question - What is the impact of study abroad on the identity formation of Chinese doctoral candidates? - we draw on the narratives of four students, selected to represent the range of participants in a larger study (Ye, 2014), recruited through personal social networks and building on Ye's insider status as a fellow PhD student and Chinese speaker. Although the selected individuals are homogeneous in terms of the stage of study and their experiences of working with students in their capacity as Teaching Assistants, they differ in other aspects of their experience such as subject specialism and where they had studied previously, and therefore help to build a fuller understanding of the identity formation of Chinese student sojourners in the UK. The interviews were conducted in Chinese. However, the quotes used in the analysis which follows have been translated by Ye and authenticated by a colleague fluent in English and Mandarin (see Ye, 2014, for the original Chinese).

Using Clandinin and Connelly's (2000) three-dimensional narrative inquiry framework, the four narratives are introduced in a form of individual trajectories of development from past to future. Each story is told using participants' original quotations, interpreted through the theoretical framework underpinning this project. As authors, what we seek from this inquiry are personal and contextual details, the linking of stories with the broader social context where these stories were enacted and the "resonance" (Conle, 1996) or dissonance readers may experience. Bearing in mind the "co-creating" nature and the "intersubjectivity" of narrative research, we have endeavoured to avoid being "narcissistic and solipsistic" (Clandinin and Connelly, 2000 , p.181), and to present the authentic voices of the participants rather than letting our own opinions to dominate.

Member-checking and triangulation based on different data sources (interviews and focus group discussions) were used in order to ensure "apparency" (Connelly and Clandinin, 1990; Van Maanen, 1988), "verisimilitude" (Polkinghorne, 1988, 1995) and "trustworthiness" (Reissman, 1993; Alasuutari, 1995).

\section{Stories of study abroad}

Two inter-related themes - self actualisation, and survival and thriving - emerge from an analysis of student narratives. We look at each in turn. 


\section{Self-actualisation}

Self-actualisation, a key concept in Giddens' 'project of the reflexive self', assumed a variety of forms in the four student narratives.

Peipei, at the age of 28 , is a final year PhD student, specialising in International Business. She comes from a small town in an east coast province of China. Having grown up in a traditional Chinese family, Peipei graduated with a BA in English for International Business from a Chinese university and went on to study for an MA in International Business in the UK before embarking on a $\mathrm{PhD}$, also at a British university. She takes pride in her decision to study abroad, reassuring herself that she has done something extraordinary, and thus achieving a sense of being a "good" and "worthy person" (Giddens, 1991, p.79). In her words,

Anyone who has the courage to do this is remarkable. We have had the courage to choose going abroad. Actually we could have an easy life in China, right? Is there anything we cannot do there, right?

She goes on to explain,

....as far as a woman is concerned, one of the most important things is to get married and have children. Of course, the earlier you get this done, the better, and of course, you will feel settled. But in the meanwhile, if you do not do this, one thing that you can expect is uncertainty. You may even wonder whether I will get married at all in my life. If I get married, what will happen, when and with whom? What I mean is that this uncertainty really is double-edged. The uncertainty will give you a sense of insecurity, but at the same time you will find it fascinating.

By choosing to study abroad, Peipei proactively seeks "the thrills of risk-taking" (Giddens, 1991, p.132) and demonstrates both her capacity as a calculating agent with the courage to take on the challenges of living and learning in an unfamiliar environment, and the ability to "disturb the fixity of things, open up new pathways, and therefore colonise a segment of a novel future" (Giddens, 1991, p.133). In short, she is motivated by a desire to pursue her personal growth and self-actualisation, a 
course of action which requires her to confront the risk of uncertainty in the hope of gain.

The motivations of Zhiqiang, a 32 year old PhD student in applied linguistics, are rather different. He has chosen to study in the UK in order enhance his career prospects and take advantage of the perceived reputation for excellence of British higher education. He studied in China for his first degree in Business English and an MA in English Studies (Applied Linguistics). He then worked as an English teacher for three years in a Chinese university before embarking on a PhD in the UK. The decision to study overseas was a significant one:

... Of course I could do my PhD in China. But a Chinese PhD degree, as far as linguistics is concerned, is less prestigious than an overseas PhD degree, which is more recognised and valued. Based on this consideration, I decided to come to the UK to do my PhD. It was mainly because I felt that I should give my career a boost. I hoped that I could get more recognition in the Chinese academic field. So I went abroad to do my PhD.

This decision is clearly consistent with the notion of an upwardly mobile career trajectory. He understands that an overseas degree is associated with greater capital and carries more symbolic power than a domestic degree in relation to employability. His "life plans" form a substantial part of a biographical narrative which is autonomous, future-oriented and career-driven (Giddens 1991).

In contrast, the decision of our third participant, 28 year old Jianjun, to study in the UK is shaped by his desire for cross-cultural experience. Jianjun holds a BSc in Engineering from a Chinese university and an MSc in Electronics and Information Engineering from a British university, where he went on to study for a PhD in Control Systems. He explains:

There are many opportunities in China, including taking the postgraduate entry examination. There are also many other opportunities. But I still chose to study abroad, because I thought it would be an experience. I wanted to see what the world was like. 
Like Peipei and Zhiqiang, Jianjun's decision to study abroad after completing his first degree is a lifestyle choice and an important part of his life-planning, guided by the goal of self-actualisation and personal development.

Our fourth participant, 28 year old Tao, originally from a northern province of China, graduated from a Chinese university with a degree in Engineering. He was then awarded an MSc in the same discipline from a British university. He explains his motivation to come to the UK in the following terms:

I had two reasons to do a PhD. Firstly, I felt my English wasn't good at all when I was awarded my Master's degree here in the UK. For example, if I went back (to China) and somebody asked me to translate something, I just could not do it. It really concerned me. Secondly, I did not think I understood many aspects of British culture since I had only been in this country for one year. If I could continue to do a PhD, I would not only be able to stay longer in the UK, but could learn something and get a doctoral degree.

Tao, then, is motivated by his desire to accumulate linguistic (English) and cultural capital. His decision making is therefore internally referential and, like the other participants, is driven by his attempt to achieve self-actualisation.

To sum up, participants' narratives suggest that they are autonomous, selfdetermined agents whose decisions to study abroad are shaped by the goal of selfrealisation. The students' active management of their life trajectories disrupts common understandings of Chinese students as 'problematic' or 'difficult to supervise'. Our findings also demonstrate that their motivations for study abroad are different from each other, indicating that Chinese doctoral students are by no means homogenous and that "we should seek to relate to them first and foremost as people" (Grimshaw, 2007, p.308; see also Tian and Lowe, 2009; Edwards and An, 2006).

\section{Surviving and thriving in a new field}

Student reflections on language issues, autonomous learning and social interaction, all recurrent themes in previous studies, demonstrate that they not only choose to 
create their desired life narrative, but are able to maintain this narrative during the course of study abroad.

\section{Perceived language problems}

Unlike many previous studies, our findings indicate that English language competency had little obvious impact on our participants' overall intercultural experience. For example, Peipei reflects:

When you first come, you feel that your language does not work, you are not good at anything and your parents are not around. But I think it takes time. Taking doing a PhD as an example, English is not your first language, but sometimes when you can actually do something better than the British students, you think you're amazing.

Rather than focusing on the academic and linguistic challenges she encountered as a non-native English speaker, Peipei thus creatively positions herself as a resilient multi-competent L2 user (Cook, 2002)

In a similar vein, Zhiqiang uses personality traits, such as self-confidence, to protect himself against potential threats to his ontological security, and to maintain the continuity of his narrative. As part of his teaching assistant role with first year students, he admits that

I, as a teacher, sometimes felt that I could not express academic concepts or terms thoroughly. Sometimes I felt that my ability fell short of my wishes ... [However], I feel that at least my subject knowledge is better than them. If they do not understand, there are surely two possibilities: either because my pronunciation is not very good, or I need to rephrase the sentence.

Sometimes in the classroom, the teacher may indulge in their own thinking and there is a lack of communication between the teacher and students. In this situation, students may not be able to understand you. However, it does not mean that you are not competent academically.

This excerpt indicates how Zhiqiang negotiates his positioning in a second language setting, where implicit unequal power relations between non-native and native speaker are embedded. He understands the limitations of his linguistic competence. However, he refuses to accept the disadvantages associated with non-native 
speakers, repositioning himself as a legitimate speaker of English with "the power to impose reception" (Bourdieu, 1977, p.75) in the classroom. In order to consolidate his claim of being confident, he further affirms his legitimacy as a non-native English teacher by invoking the "native speaker fallacy" (Phillipson, 1992, p.194):

Native speakers are not necessarily very competent TESOL teachers, because I don't think they can really understand the difficulties faced by foreign language learners, unless they really throw themselves into teaching ... For example, both listening comprehension and oral English lessons are taught by foreign teachers (i.e. native speakers) [in China]. But in many situations, comments in student's end-of-term evaluations are unsatisfactory, not even as good as Chinese teachers.

As far as Zhiqiang is concerned, language is a site where his sense of self is constructed (Weeden, 1987, p.21). Reflecting upon his overseas study experience in the UK, he feels that he has developed a sense of empowerment through drawing upon his multiple linguistic resources:

I feel strongly that I have two selves. Before I came here, I just knew that I was Chinese. I learned English as an additional language. But after three or four years of study abroad, as I was learning and reading the literature, I feel that I have developed an in-depth understanding of the word "empower", something which gives you a kind of power. So what is the power? It is the thing that allows you to master two different languages. One is Mandarin, which you can use to communicate with your relatives or people from China. It is very smooth when you communicate in your native tongue. But as a member of academic staff involved in foreign language education, on many occasions you need to read literature in English, to write in English, and even to think in English. At that moment, you think you are another person. My feeling is very strong. But this feeling is a source of power, not a burden or a distraction.

Zhiqiang thus constructs himself discursively as a bilingual (Pavlenko, 2006) and multi-competent L2 user (Cook, 2002). By taking ownership of English, his transformation enriches his self-identity and reinforces his self-esteem, providing a 
sense of ontological security and bracketing out potential threats such as the feeling of "shame" as a deficient native-speaker (Valdes 1998). Zhiqiang's narratives resonate with Pavlenko's (2003) notion of multi-competence which empowers nonnative English speaking teachers of English as a second language by allowing them to reconstruct themselves as legitimate second language users.

To sum up, paricipants stories provide support for Song's (2013, p.5) observation that "with strong personal agency, marginalized people are capable to author the world from their own perspectives, fashion themselves alternative positions in given discourses, and create more space to negotiate their legitimacy in the mainstream community." They also provide further evidence that Chinese doctoral students are not a homogeneous group.

\section{$\underline{\text { Autonomous learners }}$}

Another recurrent theme in the literature concerns the difficulties experienced by Chinese students in making the transition from teacher-led to autonomous learning. One of our participants, however, tells a rather different story of agency, reflexivity and independence. For example, Jianjun describes how he has to "make a more or less complete break with the past ... and to contemplate novel courses of action that cannot simply guided by established habits" (cf. Giddens, 1991, p.73). Entering into the new milieu, he realises that study habits developed in China cannot guide his day-to-day learning in the UK. He recalls his initial experience of studying for his Masters degree:

Indeed, I spent half a year to adapt to the new way of learning... During the second term, I wrote down every word lecturers said during the class. I wrote down all of them, non-stop, and no matter whether I could understand or not. Because the lecturers talked really fast, I just approximated the pronunciation , and then went back to check, using this as a clue to find the word. I just used this method ... What happened eventually? During the class, if lecturers slowed down a bit, I could write down the whole sentence ... Gradually, I started to get used to the lecturers... In the past I was passively receiving 
knowledge in China, but now I was actively accepting it - mastering the main points taught during the class, trying to learn what I didn't understand, and picking up useful points. So, in this way, my learning strategy was transformed.

Jianjun, then, constructs himself discursively as an autonomous learner, who actively takes on responsibility for his own learning (e.g. Little, 1991) and reflexively monitors his progress (e.g. Schunk, 2005). His openness to new things and willingness to adapt enabled him to overcome the initial "learning shock" and demonstrate both his capacity to respond to change and his personal growth. His narrative is sustained in a way which portrays him as a learner who can use his own initiative and think creatively. For him, autonomy and independence are fundamental components of self-identity formation in an intercultural setting:

Academically, my own learning methods kept changing. I spent a lot of time thinking. In the past I spent a lot of time reading, but later on I found out that it doesn't work if you just read, and you have to think. For example, when I was swimming, or when I was in the gym, I might realise suddenly what I had done was wrong, and then I wrote my thoughts down afterwards. Based on this, I went to search the literature. This way is more effective than just reading blindly and broadly.

This "small story" thus challenges the essentialist view of Chinese students as passive learners (e.g. Biggs, 1996), and, once again, demonstrates that Chinese doctoral students are not a homogenous group, who are "intrinsically 'problematic' (Goode, 2007).

\section{Social interaction}

Many previous studies focus on Chinese students' unfamiliarity with cultural normas and difficulty with social interaction. Our participant Tao's narrative, however, provides us with an alternative perspective. Like the other participants, Tao's story portrays him as a reflexive agent of late modernity, who actively manages his own project of the self, tackling the various threats posed to his ontological security, and actively accumulating various capitals. The following narrative is an example of how 
he reflexively monitors his own behaviour during a period of intercultural transition when his established habits were not a reliable guide for his actions.

... When I walk around my neighbourhood, I always smile at whoever passes by me, no matter whether I know them or not. Because I live in this area, people will get to know me eventually. A friendly gesture from me could make other people think the Chinese are really polite. British people care about this. Maybe no one knows what your name is, but I am always willing to let more British people get to know us, not like the media portray. I want them to know the Chinese are not like that, so that other people can be less biased against the Chinese.

This excerpt suggests that in intercultural encounters Tao actively "performs" the daily routines deemed appropriate in the context of the UK. This kind of "performance" or "staged routine" (Giddens, 1991, p.58) is essential to maintain a feeling of ontological security and sustain the continuity of his biographical narrative in the new context. His motivation and ability to "blend with the environment" (p.54), together with his empathy, can be viewed as a manifestation of his intercultural competence (e.g. Ruben, 1976). From the perspective of critical race theory, Tao's endeavour could also be understood as a kind of "transformative resistant capital" possessed by him, which includes "cultural knowledge of the structures of racism and motivation to transform such oppressive structures" (Pizarro, 1998; Villenas \& Deyhle, 1999, cited in Yosso, 2005, p.81).

\section{Discussion}

In offering participants a chance to "speak" to us, participant narratives challenge the essentialised view of Chinese international students as a culturally and academically homogeneous group. They help the reader gain a basic understanding of the complexity and nuances of the identity formation of participants whose experiences cannot be captured in neat typologies. Our findings not only highlight the complexity of participants' experiences, but the power of individual agency; they also demonstrate how participants create and "keep a particular narrative going" so as to achieve a coherent sense of self-identity. 
Transitional events such as study abroad require heightened reflexivity so as to maintain a "robust" sense of self-identity" (Giddens, 1991, p.55) and an awareness of the rules of the new game. Taken-for-granted or past habits can no longer reliably guide individual actions. The present study demonstrates that students' self-identity is shaped by and shapes their experience of study-abroad and provides empirical support for Marginson's (2014) assertion that international students are able to manage their lives reflexively and take ownership of their identity formation. Essentialised social categories are challenged by the multiplicity and fragmentation of self and the cultural identity created within participants' "small narratives". Moreover, the study abroad experience also facilitates the accumulation of students' personal capital, providing opportunities for self-development. In the process, unequal power relations are challenged through students' self-positioning.

Although this study is based on the experiences of Chinese students in the UK, its findings have clear implications for host institutions both here and in a range of other destinations. Listening to the stories of the participants can help inform policy and practice which, in turn, will help improve the student experience and enhance learning and personal development. Universities need to adopt multicultural inclusive practice and foster the ability of staff to see their practice from the perspectives of students; training aimed at sensitising all members of the university community to cultural differences should be given much higher priority than is currently the case (see, for instance, John 2016). By the same token, PhD students should be encouraged to develop agency, autonomy and reflexivity.

Finally, this study broadens the focus on Chinese international students. The existing literature pays very limited attention to doctoral students whose longer period of more independent study raises issues around the negotiation of identity very different from those of students on taught courses who have been the main subjects in previous research.

\section{Conclusion}

This paper set out to explore the impact of study abroad on the identity formation of Chinese doctoral candidates through the analysis of the narratives of four $\mathrm{PhD}$ students. The theoretical underpinnings provided by Giddens' (1991) "reflexive 
project of the self" and the use of narrative inquiry provided fresh insights which challenge and disrupt widespread understandings of this group of students as problematic. The resulting student narratives are defined by choice, agency, reflexivity, uncertainty and dilemma; they reveal individual motivations, aspirations, struggles, challenges, hopes, and successes in their overseas study. By offering participants a chance to "speak" to us we are better able to appreciate both the depths, nuances and complexities of their experiences, and the implications for those involved in international education.

\section{References}

Abubaker, A. 2008. The influence of Chinese core cultural values on the communication behaviour of overseas Chinese students learning English. Arecls, no. 5: 105-135.

Alasuutari, P. 1995. Researching Culture: Qualitative Method and Cultural Studies. London: Sage.

Biggs, J. 1996. Western misperceptions of the Confucian-heritage learning culture. In The Chinese Learner: Cultural, Psychological and Contextual Influences, ed. D.A. Watkins and J.B. Biggs, 45-67. CERC and ACER, Hong Kong: The Central Printing Press.

Bock, P. (ed.) 1970. Culture shock: a reader in modern psychology. New York: A. A. Knopf.

Böhm, A., Follari, M., Hewett, A., Jones, S., Kemp, N., Meares, D., et al. 2004. Forecasting international student mobility-A UK perspective. London: British Council, Universities UK and IDP Education.

Bourdieu, P. 1977. Outline of a theory of practice (trans. R. Nice). Cambridge: Cambridge University

Brockmeier, J. and Carbaugh, D. (eds) 2001. Narrative and Identity: Studies in Autobiography, Self and Culture, 1-22. Amsterdam \& Philadelphia: John Benjamins Publishing Co.

Brown, L. 2009. International education: a force for peace and cross-cultural understanding? Journal of Peace Education 1740-021X, 6, no. 2: 209-224.

Bryce, M. 2003. Defining the doctorate with Asian research students, paper presented at AARE Mini-conference, October 2-4, in Newcastle, N.S.W., Australia.

Byram, M. and Feng, A. 2006. Introduction. In Living and Studying Abroad, ed. M. Byram and A. Feng, 1-10. Clevedon: Multilingual Matters Ltd 
Campbell, J. and Li, M. 2008. Asian students' voices: An empirical study of Asian students' learning experiences at a New Zealand university. Journal of Studies in International Education 12: 375-396.

Clandinin, D. J. and Connelly, F. M. 2000. Narrative Inquiry: Experience and Story in Qualitative Research. San Francisco: Jossey-Bass Publishers

Connelly, F. M., \& Clandinin, D. J. 2006. Narrative inquiry. In Handbook of complementary methods in education research, ed. J. L. Green, G. Camalli and P. B. Elmore. Washington, D.C.: American Educational Research Association.

Connelly, M. F., \& Clandinin, J. D. 1990. Stories of experience and narrative inquiry. Educational Researcher 19, no. 5: 2-14.

Conle, C. 1996. Resonance in preservice teacher inquiry. American Educational Research Journal 33, no. 2: 297-325.

Cook, V. 2002. Portraits of the L2 user. Clevedon: Multilingual Matters

Cortazzi, M. and Jin, L. 2000. Evaluating Evaluation in Narrative, In Evaluation in Text, authorial stance and the construction of discourse, ed. S. Hunston and G. Thompson, 102-120. Oxford: Oxford University Press.

Dervin, F. 2011. A plea for change in research on intercultural discourses: A 'liquid' approach to the study of the acculturation of Chinese students. Journal of Multicultural Discourses 6, no.1: 37-52.

Ding, H. 2009. East meets West: Chinese students making sense of their cultural identity in London. Changing English 16, no. 3: 313-321

Durkin, K. 2011. Adapting to Western norms of critical argumentation and debate. In Researching Chinese learners: Skills, perceptions, and intercultural adaptations, ed. L. Jin and M. Cortazzi, 274-291. London: Palgrave Macmillan.

Edwards, V. and An, R. 2006. Meeting the needs of Chinese students in British higher education.

https://www.academia.edu/183804/Meeting_the_needs_of_Chinese_students _in_British_Higher_Education

Feng, A. W. 2009. Becoming interculturally competent in a third space. In Through education and training, ed. A. W. Feng, 71-91. Clevedon: Multilingual Matters Ltd.

Giddens, A. 1991. Modernity and Self-identity: Self and Society in the Late Modern Age. Cambridge: Polity.

Gill, S. 2007. Overseas students' intercultural adaptation as intercultural learning: a transformative framework. Compare: A Journal of Comparative Education 37, no. 2: 167-183. 
Goode, J. 2007. Empowering or disempowering the international Ph.D. student? Constructions of the dependent and independent learner. British Journal of Sociology of Education 28, no. 5: 589 - 603.

Grimshaw, T. 2007. Problematizing the construct of "the Chinese learner": Insights from ethnographic research. Educational Studies 33, no. 3: 299-311. http://dx.doi.org/10.1080/03055690701425643

Gu, Q., Schweisfurth, M. and Day, C. 2010. Learning and personal growth in a "foreign" context: Intercultural experience of international students. Compare 40, no. 1: 7-23.

HESA 2007. Students in higher education institutions. Cheltenham: Higher Education Statistic Agency.

Hockey, J. 1994. New Territory: problems of adjusting to the first year of a social science PhD. Studies in Higher Education 19, no. 2: 177-190.

Holliday, A. 1999. Small Cultures. Applied Linguistics 20, no.2: 237-264.

Hseih M. H. 2006. Identity negotiation among female Chinese international students in second-language higher education. College Student Journal 40, no. $4,870-884$.

Huang, J. C. 2010. Publishing and learning writing for publication in English: Perspectives of NNES PhD students in science. Journal of English for Academic Purposes 9, no.1: 33-44

John, T. 2016. Re-imagining the internationalisation of Higher Education: a case study of a UK university. PhD thesis, University of Reading.

Johnson, L., Lee, A. and Green, W. (2000). The PhD and the autonomous self: Gender, rationality and postgraduate pedagogy. Studies in Higher Education 25, no. 2:135-147.

Kumaravadivelu, B. 2003. Problematizing cultural stereotypes in TESOL. TESOL Quarterly 37, no. 4: 609-719.

Lin, J. G., and Yi, K. J. 1997. Asian international students' adjustment: Issues and program suggestions. College Student Journal 4: 473-379.

Little, D. 1991. Learner autonomy 1: definitions, issues and problems. Dublin: Authentik.

Marginson, S. 2014. Student self-formation in international education. Journal of Studies in International Education 18, no.1: 6-22.

Pavlenko, A. 2006. Russian as a lingua franca. Annual Review of Applied Linguistics 26: 78-99. 
Pavlenko, A. 2003. Eyewitness memory in late bilinguals: evidence for discursive relativity. The International Journal of Bilingualism 7, no. 3: 257-281.

Phillips, E. M. 1994. Quality in the PhD: points at which quality may be assessed. In Postgraduate education and training in the social sciences, ed. R Burgess. London: Jessica Kingsley.

Phillipson, R. 1992. Linguistic Imperialism. Oxford: OUP

Polkinghorne, D. 1995. Narrative configuration in qualitative analysis. In Life history and narrative, ed. J.Hatch and R. Wisniewski, 5-24. London: The Falmer Press.

Polkinghorne, D. 1988. Narrative knowing and the human sciences. New York: State University of New York Press.

Riessman, C. K. 1993. Narrative Analysis. Newbury Park, London and New Delhi: Sage Publications.

Ruben, B. D. 1976. Assessing communication competency for intercultural adaptation. Group and Organization Studies 1: 334-354.

Rudmin, F. W. 2003. Catalogue of acculturation constructs 1918-2003. In Online readings in psychology and culture (Unit 8, Chapter 8), ed. W. J. Lorner, D. L. Dinnel, S. A. Heyes and D. N. Sattler. Centre for Cross-Cultural Research, Western Washington University, Bellingham, Washington USA.

Ryan, J. and Hellmundt S. 2005. Maximising international students' 'cultural capital'. In Teaching International Students: Improving Learning for All, ed. J. Carroll and J. Ryan, 13-16. London, Routledge.

Ryan, Y, and Zuber-Skerritt, O. 1999. Supervising non-English speaking background students in the globalized university. In Supervising postgraduates from nonEnglish speaking backgrounds, ed. Y. Ryan, and O. Zuber-Skerritt, 3-11. Buckingham: Open University Press.

Schunk, D. H. 2005. Self-regulated learning: The educational legacy of Paul R. Pintrich. Educational Psychologist 40: 85-94.

Song, C. 2013. Non-Native English-Speaking Teachers' Legitimacy Negotiation in North American ELT Classrooms. SFU Education Review. http://www.sfuedreview.org/wp-content/uploads/2013/11/SongEdRev2013.pdf Accessed 20th January 2014.

Spencer-Oatey, H. and Xiong, Z. 2006. Chinese students' psychological and sociocultural adjustments to Britain: an empirical study. Language, Culture and Curriculum 19, no.1: 37-53.

Stephens, K. 1997. Cultural stereotyping and intercultural communication: working with students from the People's Republic of China in the UK. Language and Education 11, no. 2: 113-124. 
Swagler, M. A. and Ellis, M. V. 2003. Crossing the distance: Adjustment of Taiwanese graduate students in the United States. Journal of Counseling Psychology 50: 420 - 437. doi:10.1037/0022-0167.50.4.420

Tian, M. and Lowe, J. 2009. Existentialist internationalisation and the Chinese student experience in English universities. Compare: A Journal of Comparative and International Education 39, no. 5, 659-676.

UKCISA. 2015. International student statistics: UK higher education. Available at: http://www.ukcisa.org.uk/Info-for-universities-colleges--schools/Policyresearch--statistics/Research--statistics/International-students-in-UK-HE/

Valdes, G. 1998. The construct of the near-native speaker in the foreign language profession: perspectives on ideologies about language. ADFL Bulletin 29, no. 3: 4-8.

Van Maanen, J. 1988. Tales of the Field: On Writing Ethnography. Chicago: University of Chicago Press.

Vansteenkiste, M., Zhou, M., Lens, W., and Soenens, B. 2005. Experiences of autonomy and control among Chinese learners: Vitalizing or immobilizing? Journal of Educational Psychology 97: 468 - 483.

Weedon, C. (1987). Feminist Practice and Poststructuralist Theory. Oxford: Basil Blackwell.

Wright, J., and Lodwick, R. 1989. The process of the PhD: a study of the first year of doctoral study. Research Papers in Education 4, no.1: 22-56.

Wu, Q. 2014. Motivations and decision-making processes of mainland Chinese student for undertaking master's programs abroad. Journal of Studies in International Education 18, no. 5: 426-444.

Ye, L. (2014) An investigation of identity formation of Chinese doctoral students in the UK. PhD thesis, University of Reading.

Ye, L. and Edwards, V. 2015. Chinese overseas doctoral student narratives of intercultural adaptation. Journal of Research in International Education 14, no. 3: 228-241. ISSN 1741-2943 doi: 10.1177/1475240915614934

Yoon, E. and Portman, T. 2004. Critical issues of literature on counseling international students. Journal of Multicultural Counseling and Development 32: 33-44.

Yosso, T. J. 2005. Whose culture has capital? A critical ethnicity theory discussion of community cultural wealth. Race Ethnicity and Education 8, no.1: 69-91.

Yuan, W. 2011. Academic and Cultural Experiences of Chinese Students at an American University: A Qualitative Study. Intercultural Communication Studies XX, no. 1: 141-57. 